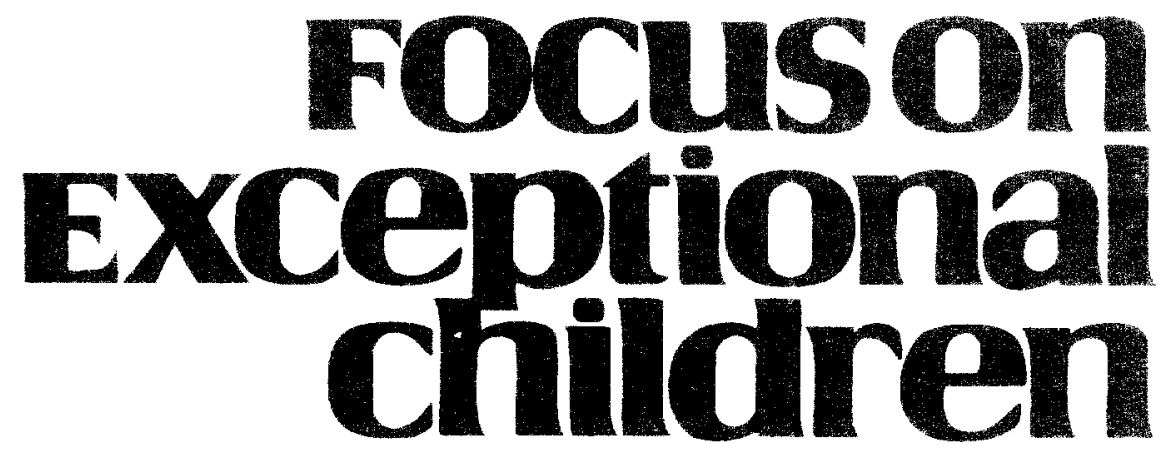

\title{
An Educator's Guide to Phonological Awareness: Assessment Measures and Intervention Activities for Children
}

\author{
Gary A. Troia. Froma P. Roth. and Steve Graham
}

While intently drawing a picture for his mother, 3-year-old Ian paused momentarily, looked up from his unfolding masterpiece, and proclaimed, "Hey-doodle and boodle. That matches!" Two-year-old Sarah, always eager to charm those in her presence, held up her favorite snack and declared with a grin, "Look! It a deanut-dutter danwich." Daniel, who exhibited the typical articulation errors of a $21 / 2$-year-old, could not correctly pronounce his younger brother's name. After several attempts, he gave up and said with much chagrin, "Nafan' is too hard to say. It has a 'th" in it." (See van Kleeck \& Bryant, 1983 and van Kleeck \& Schuele, 1987, for these and other examples.)

Delightful vignettes such as these illustrate that even toddlers are capable of making insightful observations about the sound characteristics of speech, sometimes with humorous results. Their explicit knowledge of, and ability to manipulate, the sound structure of spoken language is known as phonological awareness or metaphonological capacity. Children frequently engage in a variety of oral language activities that require phonological awareness. These include rhyming (e.g., cat-mat), alliteration (e.g., lazy lions like to lounge at lunch), blending sounds (e.g., d-o-g $\rightarrow$ dog), isolating sounds (e.g., fish $\rightarrow$ f-ish), segmenting words into their constituent sounds (e.g., chip $\rightarrow$ ch-i-p), deleting sounds (e.g., stand $\rightarrow$ sand), and substituting sounds (e.g., tap $\rightarrow$ map).

As young children playfully exploit the phonological properties of language, they fortify the underpinnings of literacy. For the beginning reader, word identification processes play a prominent role in deriving meaning from print. To decode, the written word children must map individual speech sounds onto their letter counterparts (Adams, 1990; Catts, 1991; Juel, 1991; Juel, Griffith, \& Gough, 1986; Vellutino \& Scanlon, 1991). Likewise, in the case of rudimentary spelling, the child has to encode discrete sounds into single letters or letter combinations. Thus, accurate decoding and encoding, facilitated by phonological awareness, provide children entree into the realm of literacy. For instance, children must be able to discriminate and isolate the phoneme ' $\mathrm{f}$ ' in words such as fish, foot, and fork before they fully understand that the grapheme ' $f$ ' represents this sound.

Gary A. Troia and Steve Graham are affiliated with the Department of Special Education, Lniversity of Maryland, College Park, MD 20742. Froma P. Roth is affiliated with the Department of Hearing and Speech Sciences. University of Maryland, College Park, MD 20742.

Love Publishing Company, 1998 
In recent years, phonological awareness has garnered much attention, both by researchers and by educators, because of its direct link with the acquisition of basic literacy skills. Studies have clearly demonstrated that children who perform well on sound-awareness tasks often become successful readers, whereas children who perform poorly on these tasks later struggle with word identification and spelling (Adams, 1990; Blachman, 1984. 1989; Lundberg. Olofsson, \& Wall, 1980; Mann, 1984, 1993; Share, Jorm. MacLean, \& Mathews, 1984; Stanovich. 1986; Vellutino \& Scanlon, 1987; Wagner \& Torgesen, 1987). In fact, phonological awareness in kindergarten has been established as the single best predictor of reading and spelling achievement at the end of first and second grades (Mann, 1993; Perfetti, Beck, Bell, \& Hughes, 1987; Stanovich, Cunningham, \& Cramer, 1984; Torgesen, Wagner. \& Rashotte, 1994: Wagner \& Torgesen, 1987).

In particular, phonemic awareness - the knowledge that spoken words are composed of individual sounds and the ability to manipulate these sounds-is fundamental for success in beginning reading. Phonemic awareness enables children to grasp the alphabetic principle, the concept that letters in written words correspond more or less to sounds in

\section{FOcuson Exceptional children}

ISSN $0015-511 \mathrm{X}$

FOCUS ON EXCEPTIONAL CHILDREN (USPS 203-360) is published monthly except June. July, and August as a service to teachers. special educators. curriculum specialists. administrators, and those concerned with the special education of exceptional children. This publication is annotated and indexed by the ERIC Clearinghouse on Handicapped and Gifted children for publication in the monthly Current Index to Journals in Education (CIJE) and the quarterly index. Exceptional Children Education Resoures (ECER). The full text of Focus on Exceptional Children is also available in the electronic versions of the Education Index. It is also available in microfilm from Xerox University Microtilms, Ann Arbor. MI. Subscription rates: Individual, $\$ 30$ per year: institutions. 5.40 per year. Copyright 1 1998. Love Publishing Company. All rights reserved. Reproduction in whole or part without written permission is prohibited. Printed in the United States of America. Periodicals postage is paid at Denver. Colorado. POSTMASTER: Send address changes to:

Love Publishing Company

Executive and Editorial Oftice P.O. Box 22353

Denver. Colorado 80222

Telephone (303) 221-7333

Edward L. Meyen

University of Kansas
Glenn A. Vergason

Georgia State University

Richard J. Whelan

University of Kansas Medical Center
Stanley F. Love

Publisher
Thomas S. Love

Associate Editor spoken words (Liberman \& Shankweiler, 1985; Rozin \& Gleitman, 1977). With the alphabetic principle as a foundation, children's early reading and spelling efforts, in turn, augment the development of their phonemic awareness. Thus, the relationship between phonological awareness and literacy is reciprocal (Ehri, 1987; Perfetti et al., 1987; Torgesen et al.. 1994; Wagner, 1988).

\section{AT-RISK STUDENTS}

Children at risk for reading failure and those identified with dyslexia usually perform significantly more poorly than their normally achieving peers on measures of phonological awareness (Calfee, Lindamood, \& Lindamood, 1973; Fox \& Routh, 1980; Rosner \& Simon, 1971; Zifcak, 1981). These difficulties persist even after years of traditional classroom literacy instruction, often into adolescence and adulthood (Gerber et al., 1990; Rogan \& Hartman. 1990).

Although children who are poor readers may make gains in their reading achievement with phonics instruction, these gains may be associated with better sight-word recognition and comprehension rather than improvements in metaphonology and analytic decoding skills (Alexander. Anderson, Heilman, Voeller, \& Torgesen, 1991; Ball \& Blachman, 1988, 1991). Recently, though, a growing number of intervention studies have demonstrated the effectiveness of explicit phonological awareness training for children both with and without disabilities (e.g., Elkonin, 1973; Foorman, Francis, Novy, \& Liberman, 1991; Lundberg, Frost, \& Peterson, 1988; Tangel \& Blachman, 1992; Torgesen \&

\section{STATEMENT OF OWNERSHIP, MANAGEMENT AND CIRCLLATION}

Date of Filing: November 30, 1998

Title of Publication: Focus on Exceptionial Children

Frequency of Issuc: Monthly (except June. July \& August)

Location of Known Office of Publication: $9101 \mathrm{~F}$ Kenyon Ave.. Suite 2200. Denver CO 80237

Location of Headquarters of Publisher: 9101 E. Kenyon Ave.. Suite 2200. Denver, CO 80237

Name and Address of Publisher. Editor. and Managing Editor: Stanley f. Love. $9101 \mathrm{E}$ Kenyon Ave.. Suile 2200. Denver. CO 80237

Owner: Love Publishing Company

Futent and Nature of Circulation:

Average No. Copies Each lssuc During

Total No. Copies Printed

Paid Circulation

Sales through Dealers. cte

Mail Subscription:

Total Paid Circulation

Free Distribution

Total Distribution

Office lse and Left Over

Total

2513

Filing Date

0
2071
2071
322
2393
120
2513

0
1942
1942
177
2119
81
2200

I certify that the statenents made by me above are correct and completo

(Signed) Stanley F. Love. Publister 
Davis, 1996; Torgesen, Morgan, \& Davis, 1992; see Troia, in press, for a review of methodological concerns related to these intervention studies). Research findings indicate that most children who receive such instruction make substantial headway in both decoding and spelling proficiency (e.g., Byrne \& Fielding-Barnsley, 1991, 1993, 1995; Fox \& Routh, 1976; Slocum, O'Connor, \& Jenkins, 1993; Treiman $\&$ Baron, 1983, Williams, 1980).

\section{BEHAVIORS THAT PROMOTE AWARENESS OF SOUNDS}

Although direct instruction may be desirable or necessary for some children, phonological awareness skills generally develop quite naturally during early childhood. Within a literate cultural milieu, young children engage in many routine behaviors and activities that foster the awareness of sounds in speech. These include:

- spontaneous rehearsal of spoken language, as in the following pre-sleep monologue of a toddler from Weir (1962): "Berries, not barries. Barries. Barries. Not barries, berries. Ba-ba-berries."

- reciting fingerplays (e.g., "Itsy-Bitsy Spider" and "I'm a Little Teapot")

- singing songs and chants (e.g., "This Old Man" and "Teddy Bear, Teddy Bear")

- self-initiated alliteration and rhyming (e.g., "dad, dad, stick, stad")

- spontaneous segmentation and blending, as in a recent Family Circus cartoon script: "Mirror, mirror on the wall, who's the fairest of the mall?"

- joint book reading with older children and adults

- viewing educational television programs such as Sesame Street and Shining Time Station

- exposure to environmental print (e.g., restaurant logos and street signs)

- interaction with various forms of literature (e.g.. menus, shopping lists, recipes, phone books, television viewing guides)

These behaviors and activities promote increasingly complex forms of metaphonological competence, from simple rhyming and alliteration to phonemic segmentation and blending (the developmental continuum of phonological awareness skills will be reviewed later, in the context of intervention programming). Indeed, approximately $80 \%$ of children seem to effortlessly acquire insight into the phonological structure of language without explicit teaching
(Torgesen \& Davis, 1996). Often, these children go on to experience success in traditional classroom reading and spelling curricula. The remaining $20 \%$ are not so fortunate and either need direct intervention in phonological awareness or require specialized reading/language arts instruction.

The specific objectives of an intervention program will depend on the nature and severity of the metaphonological weaknesses the child exhibits. Thus, a thorough assessment of the child's phonological awareness abilities is important.

\section{ASSESSMENT}

Before discussing specific assessment instruments, a few general caveats are in order.

1. Various instruments, both norm-referenced and criterion-referenced, evaluate different aspects of phonological awareness; some are comprehensive in scope and others assess a more limited array of skills.

2. Most commercially available tests are intended for administration to kindergarten-aged or older students rather than preschool children. Consequently, the identification of poorly developed phonological awareness in children below 5 years of age often relies on professional judgment. This situation is complicated in that scant developmental data are available to inform clinical decision-making.

3. The administration and scoring procedures of some phonological-awareness measures are quite detailed and may require considerable preparation by the examiner. Sound-blending tasks, for example, require the examiner to present individual sounds of a word while looking at the corresponding letters (e.g., $\mathrm{d}$-i-ff-er-e-n-t). For adults whose word identification skills are so highly automatized that pronouncing individual phonemes is unnatural, this conversion from an orthographic to phonemic representation of a word demands conscious effort.

4. The formats and response expectations of these tests are frequently unfamiliar to young children. Therefore, sufficient demonstration and practice must be provided prior to administration of the test to obtain a valid appraisal of a child's phonological awareness abilities. For example, a segmentation task may require a child to use wooden blocks to designate each sound in the correct sequence (e.g., wave $\rightarrow$ w [first block], a [second block], ve [third block]). A young child most likely will need training to manipulate the blocks correctly to demonstrate one-to-one correspondence with individual sounds. 
Published tests can be grouped into three broad categories based on the type of phonological awareness skills tested: rhyming, blending, and segmentation. Below, we review the most commonly used phonological awareness measures for each of these areas, beginning with tests of rhyming ability (all tests are listed in the Appendix).

The published tests reviewed are accompanied by examiner's manuals that provide detailed instructions for task administration, response scoring, and interpretation. Unless otherwise noted, the tests have adequate reliability and permit the examiner to make valid inferences about a child's test performance.

\section{Rhyming Tests}

The Phonological Awareness Test (PAT; Robertson \& Salter, 1997) is a multiability, standardized, norm-referenced test for children between 5;0 and 9;11 years of age. To our knowledge, it is the only published test that evaluates rhyming skills. The Rhyming subtest includes both rhyme judgment/recognition and rhyme production tasks. All 20 subtest items are administered.

In the rhyme judgment task, the child is asked to identify word pairs as rhyming or nonrhyming (e.g., "Do these words rhyme? Fan-man; Do these words rhyme? Boxmess.") The rhyme-production task requires the child to generate a real or nonsense word that rhymes with a stimulus word presented by the examiner (e.g., "Tell me a word that rhymes with "bat." )

Reliability and validity characteristics of the PAT are generally poor. Moreover, the test was not standardized on children with disabilities such as language impairments, learning disabilities, and mental retardation. Thus, this test may not be appropriate for distinguishing the performance differences of these populations.

\section{Blending Tests}

Two standardized, norm-referenced instruments include subtests for assessing blending skills. The WoodcockJohnson-Revised Tests of Cognitive Ability (WJ-R; Woodcock \& Johnson, 1989), an IQ measure for children as young as 2 years of age and adults, includes a Blending subtest in which the examinee is asked to blend syllables (e.g., "win-dow"), syllables plus phonemes (e.g., "ca-t"), and individual sounds (e.g., "f-oo-d"). It has 33 subtest items.

Guidelines are provided for discontinuing testing when a performance ceiling is obtained. An audiocassette is provided for item administration, and a pronunciation guide is available for live-voice presentation of the test items when necessary.

The aforementioned PAT requires the individual to blend syllables to form compound words and other mutlisyllabic words (e.g., "What word is this: doll-house?; What word is this: com-pu-ter?") as well as to blend individual phonemes (e.g., "What word is this: s-i-t?") All 20 subtest items are administered.

\section{Segmentation Tests}

The Test of Awareness of Language Segments (TALS; Sawyer, 1987) is a criterion-referenced screening test for children between 4;6 and 7;11 years of age. It consists of three subtests: segmenting sentences into words (e.g., "Use the blocks to show me 'The man came home.'"), segmenting words into syllables (e.g., "Use the blocks to show me the parts of the word 'telephone." ), and segmenting words into phonemes (e.g., "Use the blocks to show me the different sounds you hear in this word: pen.") As the verbal instructions in the examples above suggest, the child uses manipulatives (e.g., blocks or chips) to represent each isolated segment of the sentence or word. There are established rules for discontinuing item administration when a ceiling is reached.

The Test of Language Development-Primary:3 (TOLDP:3; Newcomer \& Hammill, 1997) is a norm-referenced speech and language test battery for children between ages 4;0 and $8 ; 11$ that includes a Phonemic Analysis subtest. Despite its title, this subtest actually measures a child's ability to delete syllables from compound words ("Say "airplane.' Now say it without 'air." ) All 14 test items are given. The norm tables provided suggest that children who score at the extremes of the distribution receive artificially inflated or depressed derived scores.

The aforementioned PAT has several subtests that assess children's segmentation skills, including Segmentation, Isolation, Deletion, and Substitution. Each subtest consists of two or three tasks to measure the identified skill area.

The Segmentation subtest includes tasks for segmenting sentences into words (e.g., "Clap one time for each word I say: My house is big"), words into syllables (e.g., "Clap one time for each syllable in the word "Saturday," ), and words into sounds (e.g., "Tell me each sound in "cat." )

The Isolation subtest includes tasks requiring the child to say the sound that occurs in the initial, final, or medial position of the word (e.g., "What's the ending sound in the word 'cat?" ")

The Deletion subtest has two tasks: deleting syllables from compound words or other multisyllabic words (e.g., "Say 'snowman.' Now say it again, but don't say 'man'") and deleting phonemes from words (e.g., "Say 'fox.' Now say it again, but don't say 'f." ")

The Substitution subtest requires the child to replace one sound in a word with another sound, either with or without the use of colored blocks (e.g., "This is 'map.' Use the blocks to show me how you change 'map' to 'mop.' Say 'cow'. Change 'k' to 'h." ). 
The Lindamood Auditory Conceptualization Test-Revised (LAC Test; Lindamood \& Lindamood, 1979) is an individually administered, criterion-referenced screening test that can be administered to individuals as young as kindergartenage who understand the following four concepts: same/ different, first/last, numbers to 4 , and left-to-right progression. A Spanish version of the $L A C$ is available. Minimum cutoff scores for the first and second halves of each elementary grade level are provided and are based on performance levels that predict reading and spelling success found in the research literature.

The child is required to line up colored blocks in a leftright progression in response to nonsense sequences the examiner produces (e.g., "Show me 'ip' using the blocks. Now show me 'ips.' Now show me 'vips." )

This test contains a comprehensive training phase in which the examinee becomes accustomed to manipulating the colored blocks to differentiate sounds. Guidelines for discontinuing testing are provided. A training audiocassete is provided for the examiner to practice presenting the stimuli.

The Test of Phonological Awareness (TOPA; Torgesen \& Bryant, 1994) is a standardized, norm-referenced test for children in kindergarten through second grade. Two versions are available, one for children in kindergarten (ages 5;0$6 ; 11$ ) and one for children in the early elementary grades (ages 6;0-8;11). Either version can be administered individually or in small or large groups. A response booklet is provided to the child.

For the kindergarten version, icons are used for locating each page (e.g., a clock) and each item (e.g., an apple). The examiner names the target stimulus word and the three response choices. All stimulus words are monosyllabic. The child is asked to mark with a pencil or crayon which of the three response choices begins with the same sound in the Initial Sound-Same subtest (e.g., "Mark the one that begins with the same sound as "leg." ") In the Initial SoundDifferent subtest, the child is asked to identify the picture that begins with a different sound (e.g., "Mark the one that has a different beginning sound from the other three: fork. fan, foot, shirt.")

The elementary version uses a similar format, except that the two subtests are Ending Sound-Same and Ending Sound-Different. Each subtest for each version has 10 items, all of which are administered.

\section{INTERVENTION}

When assessment findings warrant direct intervention in phonological awareness, instruction should proceed in a logical sequence of activities that require increasingly sophisti- cated metaphonological skills. Several basic training principles have been elucidated in the research literature. For example, it has been demonstrated with relative consistency that certain metaphonological skills seem to be easier than others and thus emerge earlier in a child's development. Specifically, rhyming is less difficult than sound blending, which is easier than sound segmentation, which is simpler than phoneme deletion (e.g., Stanovich et al., 1984: Swank \& Catts, 1994; Yopp, 1988).

Apparently, rhyming is the least difficult skill for children to master because it requires more implicit rather than explicit sensitivity to the phonological structure of speech and does not demand substantial cognitive resources. Phoneme deletion, on the other hand, is one of the most difficult skills to attain because it places heavy demands on working memory capacity to execute multiple cognitive operations. For example, when asked to delete the sound ' $r$ ' from the word 'bright,' a child must: (a) partition 'bright' into a sequence of smaller sound segments; (b) isolate the ' $r$ ' from this sequence; and (c) blend the remaining sounds to form the new word, 'bite.'

It also has been established that syllables (e.g., "stop") are easier for children to manipulate than intrasyllabic units of onsets and rimes (e.g., "st-op," in which "st" is the onset and "op" is the rime), which are easier to manipulate than individual sounds within the onset or rime portion of a word (Bruck \& Treiman, 1990; Fox \& Routh, 1975; Liberman, Shankweiler, Fischer, \& Carter, 1974; Rosner \& Simon, 1971; Rozin \& Gleitman, 1977; Treiman \& Zukowski, 1991, 1996). This hierarchy appears to exist because syllables are more perceptually salient than smaller segments of speech. The vowel nucleus of the syllable conveys most of the acoustic energy in the speech stream and envelopes the adjacent sounds, such that they are virtually imperceptible as distinct phonemes (Gleitman \& Rozin, 1977; Liberman, 1982; Liberman, Shankweiler, Liberman, Fowler, \& Fischer, 1977).

From a practical standpoint, training syllable segmentation and blending prior to manipulation of smaller phonological segments permits the child to become familiar with the task demands and cognitive operations intrinsic to phonological awareness activities before introducing the most difficult tasks. When working with syllables, using compounds words before other bisyllabic words is advisable because each segment of a compound word in itself is a real word, and research indicates that real words often are easier to manipulate than pseudowords (Schreuder \& van Bon, 1989; Troia, Roth, \& Yeni-Komshian, 1996; Tunmer \& Nesdale, 1982).

Other factors that seem to affect task performance include the number of sounds (or syllables) that the child must manipulate, the position of the sound in the word, and 
the articulatory characteristics of the sound to be manipulated. Specifically, it seems to be simpler for children to perform analysis or synthesis operations when a word is composed of two segments rather than three or more segments (Schreuder \& van Bon, 1989). It also seems to be easier for children to segment the initial phoneme of a word as compared to the final phoneme (most likely because of the onset-rime boundary between the first sound and the rest of the word); however, blending a final consonant onto a consonant-vowel string (e.g., "bee-t") seems to be less difficult than blending an initial consonant onto a vowel-consonant string (e.g., "sh-op"; Bruce, 1964; Helfgott, 1976; Lewkowicz \& Low, 1979; Stanovich et al.. 1984).

Finally, continuant sounds (e.g., fricatives such as "s," "sh," "th," and "v" and nasals such as "m") tend to be easier for children to segment or blend than noncontinuant sounds (e.g., stop plosives such as "b," "t," and "g" and affricates such as "ch"). Continuant sounds are perceptually more salient due to their longer duration (Marsh \& Mineo, 1977 : Skjelfjord, 1976). Along similar lines, teachers often are recommended to model slow, exaggerated pronunciation of continuant sounds (e.g., "mmmmop") and iteration of noncontinuant sounds (e.g., "t-t-t-tap") to enhance the prominence of individual sounds in words (Elkonin. 1973: Lewkowicz, 1980; Skjelfjord, 1976).

\section{Specific Intervention Tasks}

A variety of tasks may be used to train the core phonological awareness skills of rhyming, segmentation, and blending. In many cases, pictures, manipulatives such as counters, and visual cues such as squares representing the number of segments in the word (see Elkonin, 1973) can be used to facilitate a child's performance by reducing demands on working memory. Below is a list of the most commonly used tasks, arranged from, based on our experience, least to most difficult (see Lewkowicz, 1980, for a similar list and related discussion):

- Matching tasks require the child to identify which word from a given set shares the same segment as a stimulus (e.g., "Show me which picture rhymes with 'fish'; Point to the picture that ends with ' $m$ '; Which of these words begins with the same sound as "sun": tooth, sock, coat?").

- Elimination tasks (also called oddity tasks) require the child to identify which word from a given set does not share the same syllable or sound as the stimulus (e.g., "Show me which picture does not begin with ' $k$ ": Point to the picture that does not end with the same sound as 'tape'; Which of these words does not begin with 'sun': Sunday, sunshine, cowboy, sunglasses?").
- Judgment tasks require the child to give a yes/no response (e.g.. "Does "fish' rhyme with 'pot?'; Does 'cat' start with the ' $k$ ' sound?; When you put them together, do these sounds make the word 'bus?": b-us").

- Isolation tasks require the child to pronounce a certain segment in a given position of a word (e.g., "What is the first sound of "shake?"; What is the first part of "table?'; What is the sound at the end of "bench?"').

- Simple production tasks (see Yopp, 1988) require the child either to (a) generate a response that shares the same segment as a stimulus (e.g., "Tell me a word that begins with ' $t$ '; Tell me a word that ends with the same sound as 'grape'; Tell me a word that rhymes with 'hat" "), or (b) segment a word or blend segments to form a word (e.g., "Tell me each sound in the word "sheep"; Say each sound in the word 'bat' as you put a plastic chip in each of the three squares below the picture; When you put them together, what word do these two parts make: win-dow?").

- Counting tasks require the child to report the number of segments present in a stimulus word; hence. the child first must completely segment the word (e.g.. "How many sounds are in the word 'dog?'; Tap out the number of parts you hear in 'yesterday." ").

- Compound production tasks (see Yopp, 1988) require the child to execute two or more steps to produce the desired response (e.g., "Say 'play.' Now say it without 'p'; Tell me the word you get when you change the ' $f$ ' in 'fan' to ' $m$ '; Tell me the word you get when you switch the ' $k$ ' and 'p' sounds in the word 'keep'; Say 'meat.' Now say 'eat.' What sound did you leave out?").

\section{Intervention Materials and Programs}

Many commercially available intervention materials incorporate some or all of these types of phonological awareness tasks in enjoyable games and activities (see the Appendix for a list of published materials). Many of these also include activities for teaching sound-symbol correspondence and basic encoding and decoding in conjunction with phonemic awareness. Some provide lists of suggested children's literature that incorporates rhyme, alliteration, and sound play (our own list of favorites is in the Appendix).

Rather than give an overview of each, we have selected two comprehensive training programs to describe, both of which can be implemented in brief (often 15-20 minute) sessions, 2 or 3 times a week. with individuals, small groups, or large groups. The first, the Lindamood Phoneme Sequencing Program for Reading, Spelling, and Speech-Third 
Edition (LiPS: Lindamood \& Lindamood. 1998), formerly the Auditory Discrimination in Depth (ADD) program, is familiar to many practitioners and researchers. It is unique in that it places heavy emphasis on articulatory production factors. The second, DaisyQuest and Daisy's Castle (Erickson et al., 1992, 1993). is distinctive because it utilizes computer-assisted instruction with high-quality graphics, engaging sounds and music, and digitized speech.

The LiPS program is available in classroom (for up to 10 students) and clinical (for up to 4 students) versions, and is designed to be used with children who have not made progress in more traditional emergent literacy or reading/ language arts programs. The first critical step in training involves the discrimination and categorization of speech sounds on the basis of their oral-motor features and proprioceptive feedback. Through scripted Socratic dialogues with the teacher, the child is led to discover how at least a small number of vowel and consonant sounds are made. Descriptive labels and photographs highlighting the articulatory properties of each phoneme are used to classify the sounds (e.g., "tip tappers" refers to the sounds " $t$ " and "d." and "lip poppers" refers to the " $b$ " and "p" sounds).

Then the child is encouraged to attend to the actions of his or her articulators and to appropriately label how each sound is made in increasingly complex sound sequences. Colored blocks are introduced to help track the number and order of phonemes in these sequences (as in the LAC Test described earlier).

At first, the sound sequences do not form real words, so the child learns to focus on the phonological form rather than the semantic content of training items. Later during this phase of training, the child is taught to delete, add, substitute, and reverse the order of blocks to represent changes in sound sequences and words.

After the child has gained proficiency with manipulating individual sounds using the blocks, letter-sound correspondences are introduced with the aid of letter tiles and felt squares that include singleton graphemes, consonant and vowel digraphs, diphthongs, and r-controlled vowels. Once the child masters a small set of sound-symbol associations. he or she uses these to encode, and later to decode, nonsense and real words. The LiPS program is accompanied by teachers' guides and a demonstration videotape; training workshops are available for a fee.

The premise of DaisyQuest and Daisy's Castle is appealing to young children. The child's task is to find the magical dragon, Daisy, hiding in a medieval countryside (Daisy Quest) or to find her missing egg in one of the rooms of a castle (Daisy's Castle). The child chooses a character for the search and enlists the help of the wizard Oberon. Oberon guides the child through the countryside locales and castle rooms.
In DaisyQuest, the following skills are taught: rhyming, initial sounds. final sounds, and medial sounds. Daisy's Castle focuses on onset-rime blending, sound blending, and sound counting. For each skill, a tutorial as well as matching and judgment exercises are provided. A different scene is used for each exercise to maintain the child's interest. Correct responses are reinforced through verbal praise such as, "Keep it up," "Way to go," and "Super." Incorrect responses are accompanied by comments such as, "Not quite" or "That's not right." Frequently, though, more explicit error-correction procedures are necessary to improve a child's understanding and performances, so the teacher should be present throughout computer instruction.

At any time, the child can hear a stimulus word or response choice repeated simply by clicking on it. Task instructions also can be repeated. When the child has demonstrated mastery (at least five consecutive correct responses) of an activity, he or she gets a treasure or crystal as a reward, which enables the child to search for Daisy or her egg. If the child has a high error rate, he or she is directed to go back to the tutorial section for that skill.

When all of the exercises in DaisyQuest or Daisy 's Castle are accomplished, the location of the dragon or her egg is revealed in the Magic Mirror. Once the child goes to that location, a certificate can be printed to show completion of the program

The Magic Mirror also permits the child to keep track of his or her progress in the program. The child may search for Daisy or her egg as many times as desired, but subsequent attempts at each exercise following completion of the program are timed to build response automaticity, and the time limit becomes shorter with each attempt. A timer is displayed on the screen for each exercise to alert the child to this.

The software gives the instructor the ability to set up databases for separate classes and to assign activities and monitor the progress of students in each class. DaisyQuest and Daisy's Castle are accompanied by supplementary lesson plans and materials.

\section{CONCLUDING REMARKS}

Although deliberate, systematic instruction in phonological awareness may profit many children, it is not without limitations. First, spontaneous transfer from one trained phonological awareness skill such as segmentation to another untrained skill such as blending is a rare occurrence (Fox \& Routh, 1976; Slocum et al., 1993: Wagner, Torgesen, Laughon, Simmons, \& Rashotte, 1993).

Second, segmentation training in isolation or in combination with blending instruction yields positive effects on reading achievement. although blending training alone 
seems to be of relatively little value unless children already know how to segment (Fox \& Routh, 1976; Torgesen et al., 1992).

Third, research findings suggest that phonemic awareness training coupled with grapheme-phoneme correspondence instruction affords greater treatment effects in reading than phonemic awareness training alone (Bradley \& Bryant, 1983. 1985; Byrne \& Fielding-Barnsley, 1991; Cunningham, 1990; Hatcher, Hulme, \& Ellis, 1994; Marsh \& Mineo, 1977).

Fourth, not all children respond favorably to explicit instruction in segmentation and blending and, consequently, they continue to experience deficits in phonological awareness and reading or spelling, or both (Byrne \& FieldingBarnsley, 1991, 1993, 1995; Foorman et al., 1991; Torgesen et al., 1992). Although more elaborate, intensive, or prolonged instruction in phonemic awareness may help these children, an entirely different approach or combination of treatment methods may be necessary.

One final potential limitation of phonological awareness assessment and intervention involves the use of current tests and materials for children from linguistically and culturally diverse backgrounds. Assessment and instruction must be responsive to the growing diversity among children who receive school services. At present, though, educators and researchers know little about how to adapt tests and training materials to adequately accommodate these children.

For example, it is unclear how to teach metaphonological competency to children whose native language does not use an alphabetic cipher (e.g., Chinese), inasmuch as these children may have never been exposed to sound play. Of equal uncertainty is the most effective instructional approach for children who have had little opportunity to transact with printed materials.

Finally, one of the most important insights in literacy development in the last two decades is the recognition that some children have difficulty learning to read and spell because they do not possess an adequate understanding of how speech is segmented into phonemes and how these phonemes are related to print (Blachman, 1991). Consequently, it has been recommended that activities designed to promote phonemic awareness be incorporated into the general education classroom curriculum upon school entry, before children have had the chance to experience reading or spelling problems (Adams, 1990; Graham, in press; Graham \& Harris, in press). Although this article has focused primarily on the assessment and teaching of phonological awareness skills to children who do not readily acquire those skills, we would like to reiterate the importance of including explicit training in phonological awareness as an integral part of reading and spelling instruction for all children. From our perspective, this is an essential feature of exemplary early literacy instruction.

\section{REFERENCES}

Adams, M. J. (1990). Beginning to read. Cambridge, MA: Harvard University Press.

Alexander, A., Anderson, H., Heilman, P. C., Voeller, K. S., \& Torgesen, J. K. (1991). Phonological awareness training and remediation of analytic decoding deficits in a group of severe dyslexics. Annals of Dyslexia. 41 , 193-206.

Ball, E. W., \& Blachman, B. A. (1988). Phoneme segmentation training: Effects of reading readiness. Annals of Dyslexia, 38, 208-225.

Ball, E. W., \& Blachman, B. A. (1991). Does phoneme awareness training in kindergarten make a difference in early word recognition and developmental spelling? Reading Research Quarterly, 26, 49-66.

Blachman, B. (1984). Language analysis skills and early reading acquisition. In G. P. Wallach \& K. G. Butler (Eds.), Language learning disabilities in school-age children (pp. 271-287). Baltimore: Williams \& Wilkins.

Blachman, B. A. (1989). Phonological awareness and word recognition: Assessment and intervention. In A. G. Kamhi \& H. W. Catts (Eds.), Reading disabilities: A developmental language perspective (pp. 133-158). Boston: College Hill Press.

Blachman, B. A. (1991). Getting ready to read: Leaming how print maps to speech. Timonium, MD: York Press.

Bradley, L., \& Bryant, P. (1983). Categorizing sounds and learning to read: A causal connection. Nature, 301, 419-421.

Bradley, L., \& Bryant, P. (1985). Rhyme and reason in reading and spelling. International Academy for Research in Learning Disabilities Monograph Series (No. 1). Ann Arbor, MI: University of Michigan Press.

Bruce, L. J. (1964). The analysis of word sounds by young children. British Journal of Educational Psychology, 34, 158-170.

Bruck, M., \& Treiman, R. (1990). Phonological awareness and spelling in normal children and dyslexics: The case of initial consonant clusters. Journal of Experimental Child Psychology, 50, 156-178.

Byrne, B., \& Fielding-Barnsley, R. (1991). Evaluation of a program to teach phonemic awareness to young children. Journal of Educational Psychology, 83, 451-455.

Byrne, B., \& Fielding-Barnsley, R. (1993). Evaluation of a program to teach phonemic awareness to young children: A 1-year follow-up. Journal of Educational Psychology, 85, 104-111.

Byrne, B., \& Fielding-Barnsley, R. (1995). Evaluation of a program to teach phonemic awareness to young children: A 2- and 3-year follow-up and a new preschool trial. Journal of Educational Psychology: 87, 488-503. 
Calfee, R., Lindamood, P., \& Lindamood, C. (1973). Acoustic-phonetic skills and reading-kindergarten through twelfth grade. Journal of Educational Psychology, 64, 293-298.

Catts, H. W. (1991). Phonological processing deficits and reading disabilities. In A. G. Kahmi \& H. W. Catts (Eds.), Reading disabilities: A developmental language perspective (pp. 101-132). Boston: Allyn \& Bacon.

Cunningham, A. E. (1990). Explicit versus implicit instruction in phonemic awareness. Journal of Experimental Child Psychology, 50, 429-444.

Ehri, L. C. (1987). Learning to read and spell words. Journal of Reading Behavior, 19, 5-31.

Elkonin, D. B. (1973). U.S.S.R. In J. Downing (Ed.), Comparative reading (pp. 246-259). New York: Macmillan.

Foorman, B. R., Francis, D. J., Novy, D. M., \& Liberman, D. (1991). How letter-sound instruction mediates progress in first-grade reading and spelling. Journal of Educational Psychology; 83, 456-469.

Fox, B., \& Routh, D. (1975). Analyzing spoken language into words, syllables, and phonemes: A developmental study. Journal of Psycholinguistic Research, 4, 331-342.

Fox, B., \& Routh, D. K. (1976). Phonemic analysis and synthesis as word-attack skills. Joumal of Educational Psychology, 68, 70-74.

Fox, B., \& Routh, D. K. (1980). Phonemic analysis and severe reading disability. Journal of Psycholinguistic Research, 9, 115-119.

Gerber, P. J., Schneiders, C. A., Paradise, L. V., Reiff, H. B., Ginsberg, R. J., \& Popp, P. A. (1990). Persisting problems of adults with learning disabilities: Self-reported comparisons from their school-age and adult years. Journal of Learning Disabilities, 23, 570-573.

Gleitman, L. R., \& Rozin, P. (1977). The structure and acquisition of reading I: Relations between orthographies and the structure of language. In A. S. Reber \& D. L. Scarborough (Eds.), Toward a psychology of reading: The proceedings of the CUNY Conference (pp. 1-53). Hillsdale, NJ: Lawrence Erlbaum.

Graham, S. (in press). Handwriting and spelling instruction for students with learning disabilities: A review. Learning Disability Quarterly.

Graham, S., \& Harris, K. R. (in press). Prevention and intervention. In L. Baker, J. Dreher, \& J. Guthrie (Eds.), Early reading: Promoting achievement and engagement. New York: Guilford Press.

Hatcher, P. J., Hulme, C., \& Ellis, A. W. (1994). Ameliorating early reading failure by integrating the teaching of reading and phonological skills: The phonological linkage hypothesis. Child Development, 65, 41-57.

Helfgott, J. A. (1976). Phonemic segmentation and blending skills of kindergarten children: Implications for beginning reading acquisition. Contemporary Educational Psychology, 1, 157-169.

Juel, C. (1991). Learning to read and write: A longitudinal study of 54 children from first through fourth grade. Journal of Educational Psychology, 83, 437-447.

Juel, C., Griffith, P. L., \& Gough, P. B. (1986). Acquisition of literacy: A longitudinal study of children in first and second grade. Journal of Educational Psychology, 78, $243-255$.

Lewkowicz, N. K. (1980). Phonemic awareness training: What to teach and how to teach it. Journal of Educational Psychology, 72, 686-700.

Lewkowicz, N. K., \& Low, L. Y. (1979). Effects of visual aids and word structure on phonemic segmentation. Contemporary Educational Psychology, 4, 238-252.

Liberman, I. Y. (1982). A language-oriented view of reading and its disabilities. In H. Myklebust (Ed.), Progress in learning disabilities (Vol. 5, pp. 81-101). New York: Grune \& Stratton.

Liberman, I. Y., \& Shankweiler, D. (1985). Phonology and the problems of learning to read and write. Remedial \& Special Education, 6(6), 8-17.

Liberman, I. Y., Shankweiler, D., Fischer, F. W., \& Carter, B. (1974). Explicit syllable and phoneme segmentation in the young child. Journal of Experimental Child Psychology, 18, 201-212.

Liberman, I. Y., Shankweiler, D., Liberman, A. M., Fowler, C., \& Fischer, F. W. (1977). Phonetic segmentation and recoding in the beginning reader. In $\mathrm{A} . \mathrm{S}$. Reber \& D. Scarborough (Eds.), Toward a psychology of reading: The proceedings of the CUNY Conference (pp. 207-225). Hillsdale, NJ: Lawrence Erlbaum.

Lundberg, I., Frost, J., \& Peterson, O. (1988). Effects of an extensive program for stimulating phonological awareness in pre-school children. Reading Research Quarterly, 23, 263-284.

Lundberg, I., Olofsson, A., \& Wall, S. (1980). Reading and spelling skills in the first school years predicted from phonemic awareness skills in kindergarten. Scandinavian Journal of Psychology, 21, 159-173.

Mann, V. A. (1984). Longitudinal prediction and prevention of early reading difficulty. Annals of Dyslexia, 34 , 117-136.

Mann, V. A. (1993). Phoneme awareness and future reading ability. Joumal of Learning Disabilities, 26, 259-269.

Marsh, G., \& Mineo, R. J. (1977). Training preschool children to recognize phonemes in words. Journal of Educational Psychology, 69, 748-753.

Perfetti, C. A., Beck, I., Bell, L., \& Hughes, C. (1987). Phonemic knowledge and learning to read are reciprocal: A longitudinal study. Merrill-Palmer Quarterly, 33, 283-319. 
Rogan, L. L., \& Hartman, L. D. (1990). Adult outcomes of learning disabled students ten years after initial followup. Learning Disabilities Focus, 5, 91-102.

Rosner, J., \& Simon, D. P. (1971). The auditory analysis test: An initial report. Journal of Learning Disabilities, 4, 384-392.

Rozin, P., \& Gleitman, L. R. (1977). The structure and acquisition of reading II: The reading process and the acquisition of the alphabetic principle. In A. S. Reber \& D. L. Scarborough (Eds.), Toward a psychology of reading: The proceedings of the CUNY Conference (pp. 55-141). Hillsdale, NJ: Lawrence Erlbaum.

Schreuder, R., \& van Bon, W. H. J. (1989). Phonemic analysis: Effects of word properties. Journal of Research in Reading, 29, 59-77.

Share, D. L., Jorm, A. F., MacLean, R., \& Mathews, R. (1984). Sources of individual differences in reading acquisition. Journal of Experimental Psychology; 76, 1309-1324.

Skjelfjord, V. J. (1976). Teaching children to segment spoken words as an aid in learning to read. Journal of Learning Disabilities, 9, 39-48.

Slocum, T. A., O'Connor, R. E., \& Jenkins, J. R. (1993). Transfer among phonological manipulation skills. Journal of Educational Psychology, 85, 618-630.

Stanovich, K. E. (1986). Cognitive processes and the reading problems of learning disabled children: Evaluating the assumption of specificity. In J. Torgesen \& B. Wong (Eds.), Psychological and educational perspectives on learning disabilities (pp. 87-130). New York: Academic Press.

Stanovich, K. E., Cunningham, A., \& Cramer, B. (1984). Assessing phonological awareness in kindergarten children: Issues of task comparability. Journal of Experimental Child Psychology, 38. 364-370.

Swank, L. K., \& Catts, H. W. (1994). Phonological awareness and written word decoding. Language, Speech, \& Hearing Services in Schools, 25, 9-14.

Tangel, D. M., \& Blachman, B. A. (1992). Effect of phoneme awareness instruction on kindergarten children's invented spelling. Journal of Reading Behavior. 24, 233-261.

Torgesen, J. K., \& Davis, C. (1996). Individual difference variables that predict response to training in phonological awareness. Journal of Experimental Child Psychology, 63, 1-21.

Torgesen, J. K., Morgan, S., \& Davis, C. (1992). The effects of two types of phonological awareness training on word learning in kindergarten children. Journal of Educational Psychology; 84, 364-370.

Torgesen, J. K., Wagner, R. K., \& Rashotte, C. A. (1994). Longitudinal studies of phonological processing and reading. Journal of Learning Disabilities, 27, 276-286.
Treiman, R., \& Baron, J. (1983). Phonemic-analysis training helps children benefit from spelling-sound rules. $\mathrm{Mem}$ ory \& Cognition, 11, 382-389.

Treiman, R.. \& Zukowski, A. (1991). Levels of phonological awareness. In S. A. Brady \& D. P. Shankweiler (Eds.), Phonological processes in literacy: A tribute to Isabelle $Y$. Liberman (pp. 67-83). Hillsdale, NJ: Lawrence Erlbaum.

Treiman, R., \& Zukowski, A. (1996). Children's sensitivity to syllables, onsets, rimes, and phonemes. Journal of Experimental Child Psychology, 61, 193-215.

Troia, G. A. (in press). Phonological awareness intervention research: A critical review of the experimental methodology. Reading Research Quarterly.

Troia, G. A., Roth, F. P., \& Yeni-Komshian, G. H. (1996). Word frequency and age effects in normally developing children's phonological processing. Journal of Speech and Hearing Research, 39, 1099-1108.

Tunmer, W. E., \& Nesdale, A. R. (1982). The effects of digraphs and pseudowords on phonemic segmentation in young children. Applied Psycholinguistics, 3, 299-311.

van Kleeck. A., \& Bryant, D. (1983, October). A diary study of very early emerging metalinguistic skills. Paper presented at Eighth Annual Boston University Conference on Language Development, Boston.

van Kleeck, A., \& Schuele, C. M. (1987). Precursors to literacy: Normal development. Topics in Language Disorders, 7, 13-31.

Vellutino, F. R., \& Scanlon, D. M. (1987). Phonological coding, phonological awareness, and reading ability: Evidence from a longitudinal and experimental study. Merrill-Palmer Quarterly, 33, 321-363.

Vellutino, F. R., \& Scanlon, D. M. (1991). The preeminence of phonologically based skills in learning to read. In S. Brady \& D. Shankweiler (Eds.), Phonological processes in literacy: A tribute to Isabelle Y. Liberman (pp. 237-252). Hillsdale, NJ: Lawrence Erlbaum.

Wagner, R. K. (1988). Causal relationships between the development of phonological processing abilities and the acquisition of reading skills: A meta-analysis. Merrill-Palmer Quarterly, 34, 261-279.

Wagner, R. K., \& Torgesen, J. K. (1987). The nature of phonological processing and its causal role in the acquisition of reading skills. Psychological Bulletin, 101 . $192-212$.

Wagner, R. K., \& Torgesen, J. K., Laughon, P., Simmons, K., \& Rashotte, C. A. (1993). Development of young readers' phonological processing abilities. Journal of Educational Psychology, 85, 83-103.

Weir, R. (1962). Language in the crib. The Hague, Netherlands: Mouton. 
Williams, J. P. (1980). Teaching decoding with an emphasis on phoneme analysis and phoneme blending. Journal of Educational Psychology, 72, 1-15.

Yopp, H. K. (1988). The validity and reliability of phonemic awareness tasks. Reading Research Quarterly; 23, $159-177$.

Zifcak, M. (1981). Phonological awareness and reading acquisition. Contemporary Educational Psychology, 6 , $117-126$.

\section{APPENDIX}

\section{Phonological Awareness Assessment Instruments}

Lindamood, C. H.. \& Lindamood, P. C. (1979). Lindamood Auditory Conceptuali-ation Test-Revised. Allen, TX: DLM Teaching Resources.

Newcomer, P. L., \& Hammill, D. D. (1997). Test of Language Development-Priman:3. Austin, TX: Pro-Ed.

Robertson, C., \& Salter. W. (1997). Phonological Awareness Test. East Moline, IL: LinguiSystems.

Sawyer, D. J. (1987). Test of Awareness of Language Segments. Rockville, MD: Aspen.

Torgesen, J. K., \& Bryant, B. R. (1994). Test of Phonological Awareness. Austin, TX: Pro-Ed.

Woodcock, R. W., \& Johnson. M. B. (1989). WoodcockJohnson-Revised Tests of Cognitive Ability: Itasca, IL: Riverside.

\section{Phonological Awareness Intervention Materials}

Adams, M. J., Foorman, B. R.. Lundberg, I., \& Beeler, T. (1998). Phonemic awareness in voung children: A classroom curriculum. Baltimore: Paul H. Brookes.

Blevins, W. (1997). Phonemic awareness activities for early reading success. New York: Scholastic.

Blevins, W. (1997). Scholastic phonemic awareness kit. New York: Scholastic.

Byrne, B., \& Fielding-Barnsley, R. (1991). Sound foundations. Artarmon, New South Wales, Australia: Leyden Educational.

Catts, H., \& Vartiainen, T. (1993). Sounds abound: Listening, rhyming, and reading. East Moline, IL: LinguiSystems.

Catts, H., \& Vartiainen, T. (1996). Sounds abound game. East Moline, IL: LinguiSystems.

Erickson, G. C., Foster, D., Foster, K. C., Torgesen, J. K., \& Packer, S. (1992). DaisyQuest. Scotts Valley, CA: Great Wave Software.

Erickson, G. C., Foster, D., Foster, K. C., Torgesen, J. K.. \& Packer, S. (1993). Daisy's castle. Scotts Valley, CA: Great Wave Software.
Fitzpatrick, J. (1997). Phonemic awareness: Playing with sounds to strengthen beginning reading skills. Cypress, CA: Creative Teaching Press.

Lindamood, C. H., \& Lindamood, P. C. (1998). The Lindamood phoneme sequencing program for reading, spelling, and speech (3rd ed.). Austin, TX: Pro-Ed.

O'Connor, R. E., Notari-Syverson, A., \& Vadasy, P. F. (1998). Ladders to literacy: A kindergarten activity book. Baltimore: Paul H. Brookes.

O'Connor, R. E., Notari-Syverson, A., \& Vadasy, P. F. (1998). Ladders to literacy: A preschool activity book. Baltimore: Paul H. Brookes.

Robertson, C., \& Salter, W. (1995). The phonological awareness kit. East Moline, IL: LinguiSystems.

Robertson, C., \& Salter, W. (1997). The phonological awareness kit-intermediate. East Moline, IL: LinguiSystems.

Thomsen, S. (1997). SPARC (stimulus pictures for assessment, remediation, and carrover) for phonological awareness and listening comprehension. East Moline, IL: LinguiSystems.

Torgesen, J. K., \& Bryant, B. R. (1994). Phonological awareness training for reading. Austin, TX: Pro-Ed.

Wellington County Board of Education. (1995). The phonological awareness companion: Making the speech-print connection. East Moline, IL: LinguiSystems.

\section{Selected Children's Literature}

Ahlberg, J. (1979). Each peach pear plum. New York: Viking.

Bayer, J. (1984). A my name is Alice. New York: Dial Press.

Carter, D. A. (1990). More bugs in boxes. New York: Simon \& Schuster.

Carter, D. A. (1994). Alpha bugs. New York: Simon \& Schuster.

Chapman, C. (1993). Pass the fritters, critters. New York: Four Winds Press.

Cole, J. (1984). A new treasury of children's poetry: Old favorites and new discoveries. Garden City, NY: Doubleday \& Co.

Corwin, J. H. (1998). My first riddles. New York: Harper Collins.

Cromwell, L., \& Hibner, D. (1976). Finger frolics: Fingerplays for young children. Livonia, MI: Partner Press.

Dyer, J. (1996). Animal crackers: A delectable collection of pictures, poems, and lullabies for the very young. Boston: Little, Brown.

Estes, K. (1997). Silly A B seas. Bridgeport. CT: Green Bark Press.

Hague, M. (1993). Teddy bear, teddy bear: A classic action rhyme. New York: Morrow Junior Books. 
Hoberman, M. A. (1998). Miss Mary Mack: A hand clapping rhyme. Boston: Little, Brown.

Prelutsky, J. (1986). Ride a purple pelican. New York: Mulberry Paperback Books.

Riley, L. (1997). Mouse mess. New York: Blue Sky Press.

Shelby, A. (1991). Potluck. New York: Orchard.

Wells, R. (1973). Noisy Nora. New York: Dial Press. 